thinning of the diaphragm caused by substitution of its normal structure by sloughing endometrial tissue.

This report suggests that thoracic endometriosis should be suspected in any case of recurrent SP occurring in women of reproductive age, especially if right sided, even when episodes occur out of the menstrual period. The report straightens the possible risks related to the lack of recognition, inadequate management, or both of diaphragmatic endometriosis, especially in terms of possible late rupture.

\section{References}

1. Joseph J, Sahn S. Thoracic endometriosis syndrome: new observations from an analysis of 110 cases. Am J Med. 1996;100:164-9.
2. Funatsu K, Kirschner PA. Catamenial pneumothorax: can all cases be explained by the pore hypothesis? [letter]. Chest. 2003;124:766.

3. Alifano M, Roth Th, Camilleri Broet S, Schussler O, Magdeleinat P, Regnard JF. Catamenial pneumothorax. A prospective study. Chest. 2003; 124:1004-8

4. Alifano M, Venissac N, Mouroux J. Recurrent pneumothorax associated with thoracic endometriosis. Surg Endosc. 2000;14:680.

5. Roth Th, Alifano M, Schussler O, Magdeleinat P, Regnard JF. Catamenial pneumothorax: an original chest X-ray sign and thoracoscopic treatment. Ann Thorac Surg. 2002;74:563-5.

6. Kirschner P. Porous diaphragm syndromes. Chest Surg Clin North Am. 1998;8(2):449-72.

7. Muller NL, Nelems B. Postcoital catamenial pneumothorax. Report of a case not associated with endometriosis and successfully treated with tubal ligation. Am Rev Respir Dis. 1986;134:803-4.

8. Coimbra H, Brancho EC, Falcao F, De Oliveira HM. Thoracic endometriosis. Acta Med Port. 2000;13:115-8.

\title{
Integrated overlapping ventriculoplasty combined with papillary muscle plication for severely dilated heart failure
}

Yoshiro Matsui, MD, ${ }^{a}$ Yasuhisa Fukada, MD, ${ }^{a}$ Yuji Naito, MD, ${ }^{a}$ and Shigeyuki Sasaki, MD, ${ }^{b}$ Sapporo and Ishikari-Tobetsu, Japan

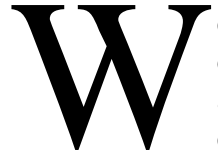

e have previously reported on the overlapping cardiac volume reduction (OLCVR) operation ${ }^{1}$ and obtained acceptable clinical outcomes. To enhance remodeling effects by changing the shape of the ventricle elliptically, we performed papillary muscle plication (PMP) combined with the OLCVR operation in 8 recent cases. This brief communication reports the favorable early results.

\section{Clinical Summary}

Eight patients ( 5 male and 3 female patients; mean age, $54 \pm 6$ years) underwent the OLCVR operation combined with PMP from March 2003. Underlying diseases were ischemic dilated cardiomyopathy (ICM) in 4 patients and idiopathic dilated cardiomyopathy $(\mathrm{DCM})$ in 4 patients. All patients had grade $3(n=4)$ to grade $4(\mathrm{n}=4)$ mitral regurgitation. The preoperative ejection fraction was $22 \% \pm 5 \%$, and the left ventricular (LV) diastolic dimension was $72 \pm 4 \mathrm{~mm}$, as evaluated by means of echocardiography. The

From the Department of Cardiovascular Surgery, ${ }^{\text {a }}$ NTT East Corporation Sapporo Hospital, Sapporo, Japan, and the Division of Medical Sciences, ${ }^{\mathrm{b}}$ Health Science University of Hokkaido, Ishikari-Tobetsu, Japan.

Received for publication Sept 22, 2003; revisions requested Oct 17, 2003; accepted for publication Oct 23, 2003.

Address for reprints: Yoshiro Matsui, MD, Department of Cardiovascular Surgery, NTT East Corporation Hospital, S1W15, Sapporo, Japan 060-0061 (E-mail: yoshirou_matsui@smc.mhc.east.ntt.co.jp).

J Thorac Cardiovasc Surg 2004;127:1221-3

$0022-5223 / \$ 30.00$

Copyright $\odot 2004$ by The American Association for Thoracic Surgery doi:10.1016/j.jtcvs.2003.10.044

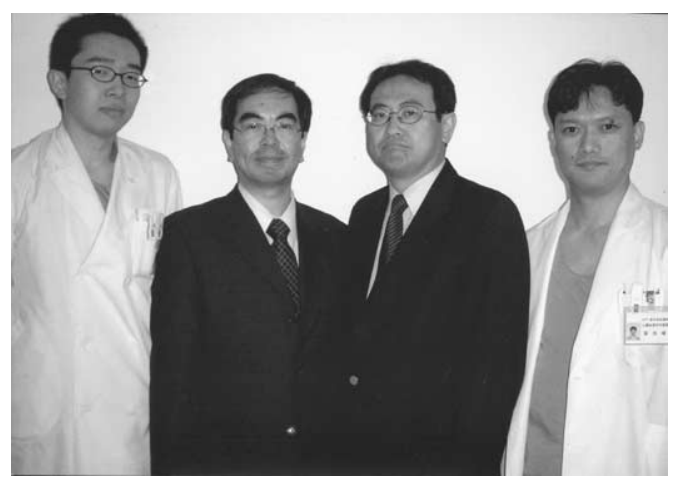

Drs Naito, Sasaki, Matsui, and Fukuda (left to right)

LV end-diastolic volume index, assessed by means of left ventriculography, was $198 \pm 42 \mathrm{~mL} / \mathrm{m}^{2}$. Preoperative New York Heart Association functional class was III in 3 patients and IV in 5 patients, including 2 catecholamine and intra-aortic balloon pump (IABP)-dependent patients. Emergency operations were performed for 2 patients.

Informed consent was obtained before the operation and after full explanation. Mitral annuloplasty with an undersized artificial ring was performed in all patients during blood cardioplegic arrest. Next, a 10-cm-long incision was made along the left anterior descending coronary artery in the enlarged LV free wall. Through the incision, PMP was carried out with 3 autologous pericardiumpledgeted mattress sutures. These sutures were placed through the trabeculae around the bases of the anterior and posterior papillary muscles, with the deepest being just below the site of chordal attachment. The left marginal incision was then continuously su- 

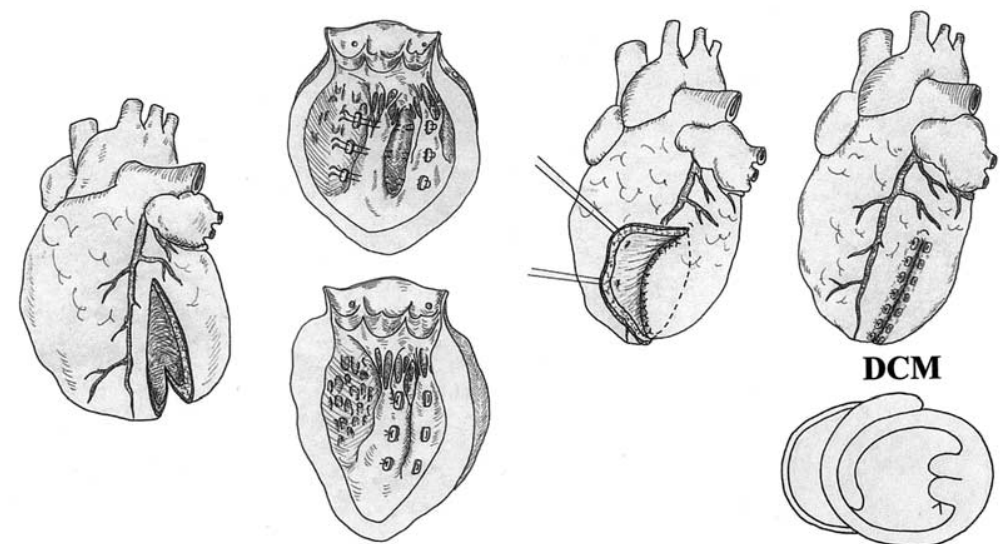

DCM
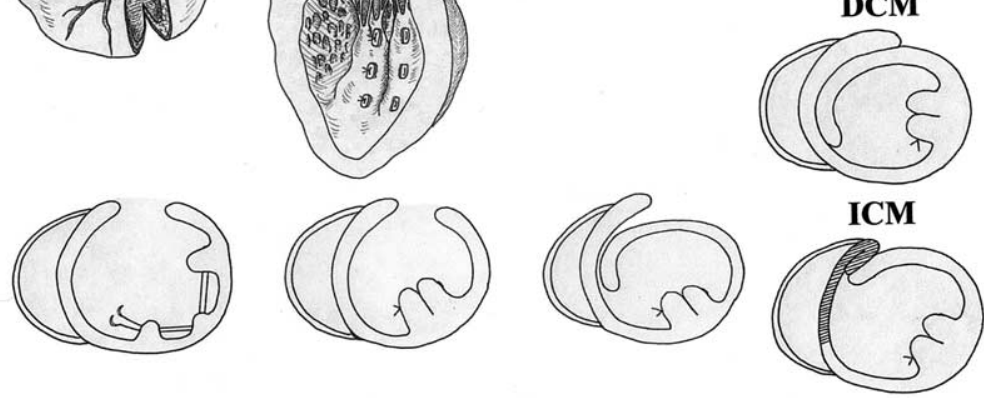

Figure 1. Schema of integrated overlapping ventriculoplasty combined with PMP. The excluded septum can be overlapped in a fairly wide extent in case of idiopathic DCM because it might possess a potential ability to assist cardiac function. In contrast, the right marginal incision in a patient with ICM is attached close to the suture line to achieve its reinforcement and hemostasis because the scarring septum might restrict the motion of the LV anterior wall if overlapped extensively. See text for details.
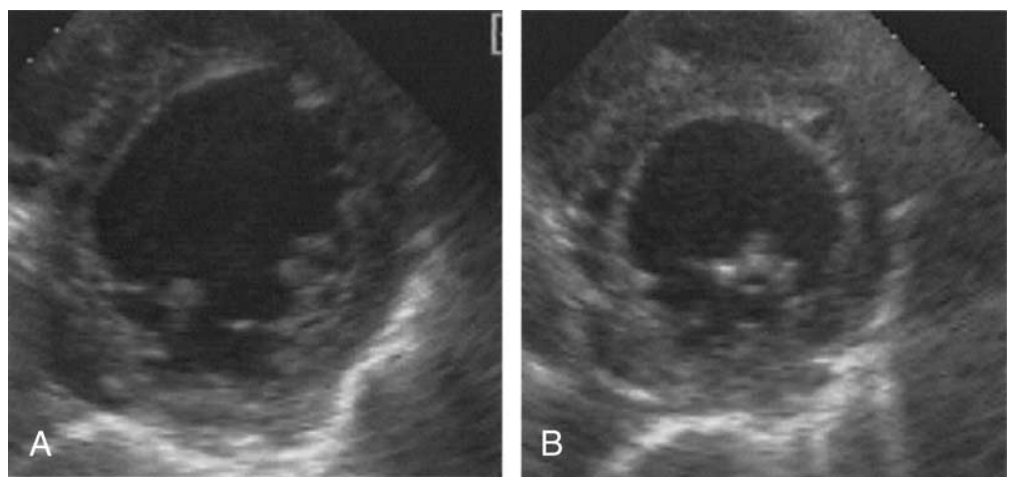

Figure 2. Echocardiographic images before and after the operation in a patient with ICM: A, preoperative echocardiography at the level of the papillary muscle; B, postoperative echocardiography exhibiting the decreased ventricular diameter and the papillary muscles remaining bundled together.

tured to the lower two-thirds height of the septal wall. The right marginal incision was attached to the epicardium to cover the ventricular free wall with pledgeted mattress sutures in DCM. In ICM a felt strip was placed between the left marginal incision and overlapped the right marginal incision (Figure 1). These procedures were followed by proximal anastomosis of coronary revascularization or tricuspid annuloplasty if necessary after declamping of the aorta. Concomitant procedures included aortic valve replacement in 2 patients, tricuspid annuloplasty in 7 patients, and coronary artery bypass grafting in 4 patients.

All data for continuous variables are expressed as means \pm SEM. Differences between preoperative and postoperative values were compared with paired $t$ tests and the Wilcoxon rank test.

\section{Results}

Seven of 8 patients were weaned from bypass without IABP or percutaneous cardiopulmonary bypass support (PCPS). Medical inotropic support was required in some cases using only noradrenaline and milrinone. One patient who had a cardiac arrest preoperatively required both IABP and PCPS postoperatively. Although this patient was weaned from IABP and PCPS postoperatively, the patient died 2 months after the operation as a result of irreversible cerebral damage. The other 7 patients recovered well and have been followed for $102 \pm 26$ days. The current New York Heart Association functional class is I in 6 patients and II in 1 patient $(P<.01$ vs preoperative status). Postoperative ventricular arrhythmias were rarely seen, even in 
patients with recurrent ventricular tachyarrhythmias preoperatively.

Postoperative hemodynamic data in survivors are as follows: ejection fraction of $37 \% \pm 8 \%$, LV end-diastolic volume index of $132 \pm 20 \mathrm{~mL} / \mathrm{m}^{2}$, and $\mathrm{LV}$ diastolic dimension of $64 \pm 4 \mathrm{~mm}$. These values were significantly improved postoperatively $(P<$ $.05)$. No mitral regurgitation was revealed in the latest echocardiography performed in survivors postoperatively. Figure 2 shows a postoperative echocardiographic image showing the papillary muscles remaining bundled together.

\section{Discussion}

The influences and clinical significance of partial left ventriculectomy on cardiac function are controversial. ${ }^{2}$ We have developed the OLCVR operation to avoid the resection of potentially viable myocardium and the left circumflex coronary artery. ${ }^{1}$

Recently, Buckberg and colleagues ${ }^{3}$ reported that the conversion of the elliptical to spherical LV substrate might be responsible for ICM or DCM. Enlargement of the apex with a thin wall might precipitate the converting process from the elliptical to spherical LV shape. Because our OLCVR operation doubles, in part, the LV anterior wall around the apex, it has the advantage of reducing the circumferential diameter and increasing the wall thickness.

However, the OLCVR operation alone could not reduce the basal dimensions of an enlarged left ventricle effectively because of its features. We thus added PMP to the OLCVR operation to enhance the remodeling effects of the ventricle. The procedure of PMP presented here has been reported as a new volume reduction surgery by Nair and associates. ${ }^{4}$ Meticanti and colleagues ${ }^{5}$ recently reported favorable results of the surgical approach, consisting of endoventricular mitral repair, ventricular reconstruction, and coronary artery bypass grafting. Our operative procedure is rather different from their procedure regarding the method of mitral repair and LV reconstruction, but the aim of operation is similar. We currently consider the OLCVR operation combined with PMP to be relatively safe and effective for selected patients with severely dilated failing hearts, although long-term follow-up is mandatory.

\section{References}

1. Matsui Y, Fukada Y, Suto Y, Yamauchi H, Luo B, Miyama M, et al. Overlapping cardiac volume reduction surgery. J Thorac Cardiovasc Surg. 2002;124:395-7.

2. Franco-Cereceda A, McCarthy PM, Blackstone EH, Hoercher KJ, White JA, Young JB, et al. Partial left ventriculectomy for dilated cardiomyopathy: is this an alternative to transplantation? J Thorac Cardiovasc Surg. 2001;121:879-93.

3. Buckberg GD, Coghlan HC, Torrent-Guasp F. The structure and function of the helical heart and its buttress wrapping. V. Anatomic and physiologic considerations in the healthy and failing heart. Semin Thorac Cardiovasc Surg. 2001;13:358-85.

4. Nair RU, Williams SG, Nwafor KU, Hall AS, Tan L. Left ventricular volume reduction without ventriculectomy. Ann Thorac Surg. 2001;71: 2046-9.

5. Menicanti L, Di Donato M, Frigiola A, Buckberg G, Santambrogio C, Ranucci M, et al. The RESTORE Group. Ischemic mitral regurgitation: Intraventricular papillary muscle imbrication without mitral ring during left ventricular restoration. J Thorac Cardiovasc Surg. 2002;123:104150. 